\title{
Stage IV Pharyngeal Cancer
}

National Cancer Institute

\section{Source}

National Cancer Institute. Stage IV Pharyngeal Cancer. NCI Thesaurus. Code C8771.

Stage IV carcinoma of the pharynx according to the American Joint Committee on

Cancer, 6th, 7th, and 8th editions. 